Несмотря на снижение нормативов мгновенной и текущей ликвидности за анализируемый период ПАО «Сбербанк России» с запасом соблюдает предельные значения обязательных нормативов ликвидности, установленные Банком России[3, с. 54].

В целом оценка коэффициентов эффективности активных операций ПАО «Сбербанк России» за 2017-2018 гг. показала положительную динамику всех показателей, все расчетные значения удовлетворяют оптимальным значениям. Это говорит о том, что произошло повышение активности ПАО «Сбербанк России» в области активных операций, что может в перспективе положительно сказаться на уровне доходности банка.

Для выхода банка на лидирующие позиции на рынке к 2020 г. ПАО «Сбербанк России» стоит двигаться в сторону универсализации, задумываться о роли розничного бизнеса и повышении его рентабельности.

Помимо очевидных путей привлечения клиентов в высококонкурентной среде, ПАО «Сбербанк России» стоит сфокусировать свои усилия на кросс-продажах (увеличении количества продуктов на одного клиента) и построении долгосрочных отношений с клиентами. У очень многих банков идентичные задачи - довести количество продуктов на одного клиента до среднеевропейского уровня, что представляется довольно сложной задачей. При этом степень проникновения банковских услуг и продуктов остается низкой: наше исследование показало, что житель крупного российского города является в среднем клиентом трех банков.

Таким образом, анализ и управление активами коммерческих банков является неотъемлемой и важнейшей частью финансового, банковского менеджмента, и позволяет уменьшить финансовые риски кредитных организаций, оптимизируя структуру баланса с целью обеспечения высокого уровня эффективности банковских операций при одновременном сокращении издержек и соблюдении действующих ограничений по рискам.

$$
* * *
$$

1. Аврахова Ю.В. Методика анализа активных операций коммерческого банка//Наука, образование и культура. 2017. № 1 (16). С. 25-27.

2. Должиков А.Л. Методика проведения анализа активных операций коммерческого банка//Наука через призму времени. 2017. № 6 (6). С. 22-25.

3. Куренков Д.В., Сергеева М.С. Оценка активных операций ПАО «Сбербанк России»//В сборнике: Совершенствование финансово-кредитного механизма регионов Сборник материалов Всероссийской заочной научно-практической конференции . 2017. С. 50-55.

4. Рабаданова С.А. Анализ активных операций коммерческого банка//В сборнике: Финансовые инструменты регулирования социально-экономического развития регионов. Сборник материалов II Всероссийской научно-практической конференции. 2017. С. 316-318.

5. Официальные данные бухгалтерской отчетности ПАО «Сбербанк России» за 2017-2018 гг. [Электронный ресурс] Режим доступа: http://www.sbrf.ru/ (дата обращения: 26.11.2019)

\title{
Бабурян К.В.
}

\section{Влияние мотивации персонала на сокращение текучести кадров на предприятии}

ФГБОУ ВО «Башкирский государственный университет»

(Россия, Уфа)

doi: $10.18411 / \mathrm{l}-12-2019-63$

idsp: ljournal-12-2019-63

Научный руководитель Алексеев O.A.

\section{Аннотация}

В статье рассмотрены взаимосвязь текучести кадров и системы мотивации. Выявлены основные причины текучести кадров, а так же факторы удовлетворенности трудом на предприятии. Приводятся доводы о недостаточности существующих 


\section{инструментов к определению значения коэффициента текучести кадров на предприятии. \\ Ключевые слова: мотивация, текучесть кадров, стимулирование персонала, организация}

На сегодняшний день специалисты в области управления человеческими ресурсами связывают одну из причин высокого коэффициента потери кадров на предприятиях с растущим среди сотрудников недовольством соотношения выполняемого объёма работы к величине получаемой заработной платы, а также с использованием неадекватной, непонятной для сотрудников системы мотивации труда.

Мотивация и стимулирование персонала, а также, как результат, сплоченная деятельность всего коллектива - это прямой путь к преодолению всех трудностей и к выходу бизнеса на более высокий уровень, где откроются новые возможности.

Мнение работников предприятий относительно ценности мероприятий в рамках повышения мотивации может существенно расходиться с представлениями руководства Следствием высокой текучести кадров, в большинстве случаев, является снижение уровня общей квалификации работников предприятия, недостаточный уровень взаимопонимания между сотрудниками, снижение производительности труда, и, как результат, снижение финансово-экономических показателей деятельности предприятия. Умело управляя персоналом, можно значительно усовершенствовать организацию производства и, тем самым, повлиять на финансовые результаты предприятия [2, с. 12].

Считается, что к основным потребностям человека относят физиологические потребности и потребность в безопасности, конкурентное сражение в современных реалиях выигрывают спрос на высокую заработную плату или получение премий, бонусов, надбавок.

Как мы понимаем, самый эффективный стимул - это оплата труда. Но, на успокоение сотрудников компаний, ТК РФ запрещает дисциплинарные наказания в виде урезания оклада. Именно поэтому многие работодатели сейчас делают зарплату на своем предприятии нефиксированной, а сдельной или мотивационной, включающей премии. При таком способе оплаты труда сотрудники старательнее выполняют свою работу и пытаются делать это качественнее.

Повышение зарплаты за счет премии не только увеличивает эффективность работы, но и стимулирует совершенствование сотрудника в своей профессии. Система премии на каждом отдельном предприятии уникальна и обладает своими особенностями.

Что же такое мотивация? Это понятие означает, что у человека происходит внутреннее формирование личных, побуждающих к повышению эффективности труда, моментов. Каждого человека могут мотивировать разные факторы в зависимости от его потребностей. Таких факторов может быть сразу несколько у одного человека.

Факторы мотивации имеют классификацию, подразделяющую их на внешние и внутренние.

Процесса самомотивации может быть недостаточно, поскольку для того, чтобы в человеке не угасало стремление развиваться и совершенствоваться его текущие заслуги и результаты должны постоянно подкрепляться каким-либо вознаграждением. Очевидным представляется факт, что текучесть персонала напрямую связана с мотивацией работников. В качестве мероприятий по повышению мотивации, как правило, используются меры, учитывающие рост потребности работников в возможности реализовать их профессиональные, творческие способности и получить в ответ вознаграждение и компетентностную оценку руководством [3, с. 40].

На практике в области материального стимулирования применяют следующие мероприятия: 
1) ежемесячные выплаты надбавок, бонусов отличившимся сотрудникам; ожидание от данного мероприятия - заинтересованность сотрудников выполнять качественно должностные обязанности;

2) выплата премий за инновации; ожидание - со стороны сотрудников продвижение и реализация выдвинутых инициатив, реализация своего творческого потенциала в организации;

3) ежегодные выплаты премий за стаж работы; ожидание - снижение текучести кадров, создание постоянного штата сотрудников;

4) выплата стимулирующих надбавок и доплат за совмещение работы отсутствующих сотрудников либо расширение зоны обслуживания при совмещении аналогичной должности, надбавок за учёную степень, доплат за наставничество; ожидание - увеличение лояльности сотрудников к работодателю;

5) денежные компенсации особых условий труда: за разъездной характер работы, за вредные условия труда; ожидание - повышение доверия к работодателю, снижение текучести кадров и создание сплочённого коллектива.

Несмотря на большие дополнительные расходы на премирование и компенсации работникам, в реальности их величина может быть вполне доступна для предприятия.

В качестве нематериальной мотивации применяют следующие мероприятия:

- предоставление первоочередной возможности выбора времени отпуска; ожидаемый эффект - повышение производительности труда, повышение социальной активности;

- прозрачная, понятная всему штату сотрудников система оплаты труда; ожидание - повышение лояльности сотрудников к работодателю.

- организация отдыха работников и членов их семей, например, организация и частичная оплата поездок сотрудников и их детей на развлекательные мероприятия в другие города; ожидаемый эффект формирование у работников ощущения «заботы» об их досуге со стороны руководства предприятия, создание причастности к единой команде [1, с. 109].

Ситуация с изменением кадрового состава в сторону понижения эффективности труда сотрудников является первым признаком нецелесообразного управления кадровым потенциалом предприятия. Однако, нередка ситуация, при которой предприниматели, управленцы и владельцы фирм используют «текучку кадров» как механизм уменьшения издержек на содержание квалифицированного персонала. Кроме того, давно замечена закономерность, когда начальники, которые позволяют в своей компании, либо в своем подразделении частую смену действующего персонала, в большинстве своем, сами не являются людьми постоянными и, как правило, неспособны на выстраивание долгосрочных отношений. С кем бы им не приходилось иметь дело, им гораздо проще отказаться от сотрудничества либо взаимодействия с тем или иным работником, нежели, изменить себя и свое отношение к сложившимся обстоятельствам.

Для улучшения ситуации с постоянно уходящими из компании сотрудниками и получения возможности регулировать интенсивность оттока персонала из компании, прежде всего, необходимо понять и определить причины увольнения персонала. В качестве первостепенной причины можно назвать несоответствие ожиданиям сотрудников условий труда или уровня вознаграждения, например, слишком низкая заработная плата, или некомфортные условия труда, в которых приходится работать, либо отсутствие возможности продвижения по карьерной лестнице.

C приходом новых сотрудников в компанию и уходом работников с большим опытом значительно снижается производительность труда, поскольку за короткое 
время не всегда удается адаптироваться к требуемому уровню нагрузки. Как следствие, происходит потеря потенциальной прибыли компании. Подобные результаты также ожидаются, когда опытные и квалифицированные сотрудники обучают новых и тратят излишнее время именно на «воспитание» сотрудника, а не на выполнение трудовых обязанностей. Кроме этого, к негативным последствиям «кадровой текучки» относят ухудшение микроклимата в коллективе.

Исследуя проблему высокой текучести кадров на промышленных предприятиях, необходимо отметить:

- на предприятиях недостаточно внимания уделяется выявлению причин текучести кадров и поиску реальных и действенных методов и форм снижения данного показателя;

- в рамках мероприятий по выявлению факторов мотивации работников в большинстве случаев исследуются факторы, которые либо хорошо известны руководителям предприятия, либо не нарушают их представления о том, какими должны быть пожелания и потребности работников;

- применение мер по повышению мотивации, разработанных на основе пожеланий работников могут существенно снизить текучесть кадров, повысить производительность труда [4, с. 125].

Приведем пример существующей системы мотивации сотрудников, практикуемой на одном из производственных предприятий применяются следующие способы мотивации персонала:

1. Сотрудникам, показавшим высокую работоспособность (выполнение поставленных задач и планов), начисляется дополнительная премия в размере $10 \%$ от заработной платы.

2. Всем сотрудникам выдается полис добровольного медицинского страхования, позволяющий за счет работодателя посещать стоматологов, проводить плановые операции, диагностические обследования.

3. Производится частичная оплата расходов за услуги фитнес-клубов, посещаемых сотрудниками.

4. Работникам и членам их семей предоставляются путевки в профилактории, санатории и дома отдыха.

5. За выслугу лет сотрудники награждаются именными памятными подарками.

6. Предоставляются специальные ипотечные условия, позволяющие часть займа оформить без начисления процентов.

7. Поощряется карьерный рост сотрудников, показывающих свой профессионализм, приверженность корпоративным ценностям и целеустремленность.

8. Проводится регулярное обучение сотрудников с целью повышения квалификации и приобретения новых навыков. Отличившихся работников отправляют учиться не только в другие города, но и страны.

9. Поздравления сотрудников со значимыми датами (дни рождения, заключение брака, рождение детей).

Таким образом, оценка существующей системы мотивации на предприятии показала, что предприятие пытается применять различные виды мотивации работников: материальное стимулирование, социальное стимулирование, моральное стимулирование. Однако стоит отметить, что:

- используются далеко не все возможные формы мотивации труда работников; 
- реализация даже заявленных форм мотивации применяется в довольно ограниченных рамках;

- требуется исследование возможности использования дополнительных форм мотивации работников.

Результаты исследования могут способствовать принятию руководством обоснованных решений по снижению текучести кадров, формированию лояльного, активного, творческого, нацеленного на инновации и открытого для общения с руководством персонала.

$$
* * *
$$

1. Базык Е.Ф. Снижение текучести кадров в современных экономических условиях / Базык Е.Ф., Сазонова Д.И. //Актуальные ?проблемы? гуманитарных и есте?ственных наук. Москва: Научнои?нформационный издат?ельский центр и редакция? журнала «А?ктуальные проблемы гуманитарных и естественных наук». 2018. № 9. С. 109-115.

2. Голубков Е.П. Анализ текучести кадров на предприятии/ Е.П. Голубков// Менеджмент в России. 2018. №3. С. 12-14.

3. Султанова А.В., Трошина Е.П. Методики диагностики мотивации персонала организации // Научное обозрение. - 2017. - №13. - С. 40-48.

4. Щанина Е.В. Текучесть персонала как один из основных показателей эффективности ?работы ?с персона?лом / Щ?анина Е. В?., Синева А. Г. ? // Традици?онное, с?овремен?ное и пер?еходное в? условиях? модерниз?ации росс!ийского эобщества?: сборник статей XII Всероссийской научнопрактической конференции. - Пенза: Приволжский Дом знаний, 2018. С. 125-128.

\section{Байгузина Л.3., Вечтомова Я.Д. \\ Сущность и методы снижения финансовых рисков предприятия}

ФГБОУ ВО «Башкирский государственный университет» (Россия, Нефтекамск)

doi: $10.18411 / l j-12-2019-64$

idsp: ljournal-12-2019-64

\section{Аннотация}

В статье уточнено и обосновано значение категории «финансовый риск», дана авторская трактовка финансового риска, рассмотрены методы снижения финансового риска.

Ключевые слова: финансовый риск, классификация, ущерб, потери, финансовая деятельность.

\section{Abstract}

The article clarifies and substantiates the meaning of the category «financial risk», gives an author's interpretation of financial risk, considers methods of reducing financial risk.

Keywords: financial risk, classification, damage, loss, financial activity.

Неотъемлемая часть осуществления хозяйственной деятельности предприятием - возможность (вероятность) утраты им части своих доходов, ресурсов или проявление дополнительных затрат в результате проведения конкретной производственной и финансовой тактики или стратегии, то есть возникновения риска.

Финансовые потери имеют место при наличии прямого денежного ущерба, связанного с перерасходом денег, непредусмотренными платежами, выплатой штрафов, уплатой дополнительных налогов, утерей денежных средств и ценных бумаг. Одновременно финансовые потери проявляются при неполучении денег из тех источников, откуда они должны были быть получены, при невозврате долгов, неоплате покупателем поставленной ему продукции, уменьшении выручки вследствие снижения цен на реализуемую продукцию, товары, услуги. Особые виды денежного ущерба 